\author{
Rafal Kowalik \\ dr inż. \\ Wyższa Szkoła Oficerska Sił Powietrznych w Dęblinie \\ Katedra Awioniki i Systemów Sterowania \\ r.kowalik@wsosp.pl
}

\title{
Emil Sadowski
}

mgr inż.

P.U.H. HESTA

emil@hesta.com.pl

DOI: $10.35117 /$ A_ENG_17_10_05

\section{Mathematical modeling and analysis of dynamic phenomena turnout rail}

\begin{abstract}
The article presents the results of simulations carried out for the developments on the railway junction in the instantaneous passage of a railway vehicle. The main focus lies on getting runs all three forces present in the area of the point of contact wheel-rail. Tests carried out for different vehicle speed rail-track. In addition, also presented mathematical models describing the motion of the train to pass through the railway track and discusses the mathematical considerations describing the deflection of the beam under the influence of rolling wheels on it. At the end shows the conclusions of the simulations.
\end{abstract}

Keywords: Railway track; The wheel rail contact; Normal force

\section{Introduction}

Ongoing modernization works of the railway infrastructure in Poland are designed to adapt it to increase the permissible speed of train passage through the tracks. It is also connected with changes in the construction of switch-points and increasing the holding force of the spire itself. The next problems in connection with the introduction of high-speed rail in Poland include the assessment of track wear and the assessment of their flexibility for moving trains at high speed. In view of these activities, it is necessary to estimate the condition of the existing railway infrastructure and to conduct a dynamic analysis of the train running on it at speeds above $250 \mathrm{~km} / \mathrm{h}$.

\section{The wheel rail contact}

An important issue to be addressed when discussing switch mechanisms is the analysis of the contact area of the wheel with the main rail at the moment of passing the trolley wheels that are part of the train on the spire simultaneously. This issue in relation to the wheel rail contact itself was discussed, inter alia, in publications [4], [5], [6] and [7], and the same aspect of contact of the wheel with track elements included in the switch mechanism has not been sufficient enough although at least some of the relevant news on this subject can be found in the publication [1] and [12]. 


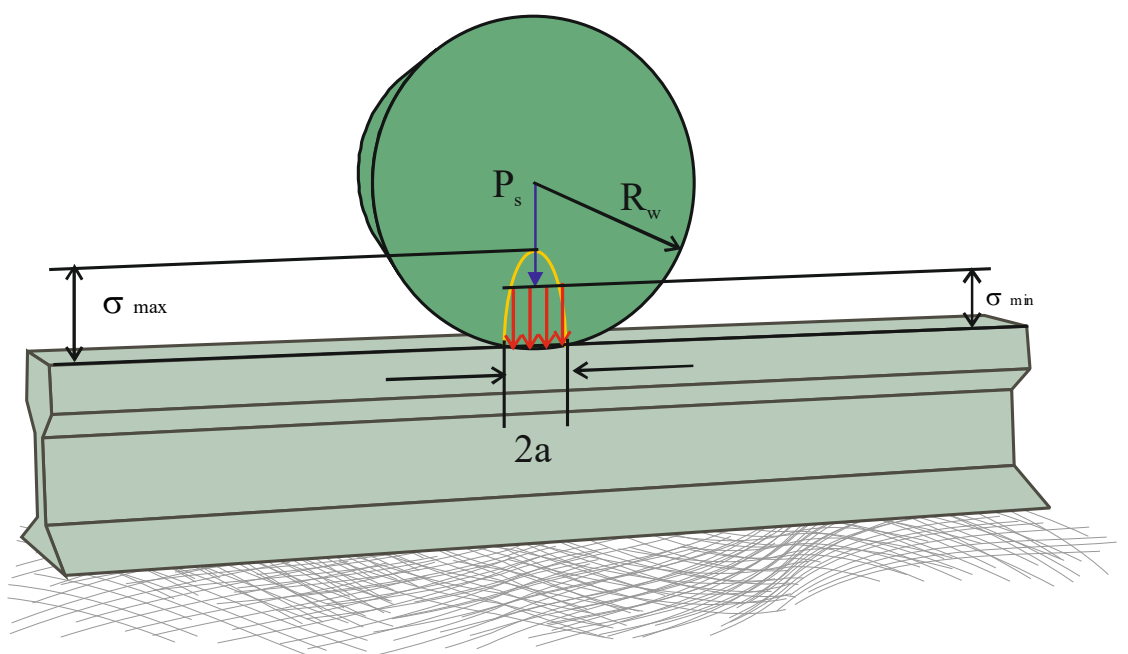

1. Technical data occurring in the phenomenon of rail contact with the wheel [10]

Based on available Hertz's theories, Eisenmann derived a relationship from which the total contact area of the wheel and rail can be determined [10]:

$$
\sigma_{\text {średnie }}=\frac{P_{s} \cdot 10^{3}}{2 a \cdot 2 b}
$$

where $2 b[\mathrm{~mm}]$ is the width of the railway wheel for which the contact surface is determined. In Eisenmann's considerations, it was assumed that $2 b=12 \mathrm{~mm}$, therefore the value $2 a$ can be determined from the expression:

$$
2 a=3,04 \cdot\left[\frac{P_{s} \cdot R_{w} \cdot 10^{3}}{2 b E}\right]^{0,5}
$$

It should be noted that the values of loads exerted by the wheel of the railway wagon truck exceed the yield limits of the material from which the wheel or rail was made. In such cases, the plasticity of the plane resulting from the contact between the wagon wheel and the rail is distorted, and this is because of the deformations occurring on the surface of the rail as a result of contact forces, including friction forces.

Taking the above assumptions into account, it can be assumed that the area created in the wheel rail contact will be a rectangle with a length of $2 a$ and width $2 b$ assuming that the contact of the wheel with the rail on all bogie wagons lasted similar times and took place under identical conditions. Of course, the materials from which both elements were made, did not lose too much on their plasticity as a result of changes in the ambient temperature.

Hence, the dependence on the calculation of the duration of the wheel rail contact is as follows [10]:

$$
2 a=3,19 \cdot\left[\frac{P_{s} \cdot\left(1-v^{2}\right) R_{w} \cdot 10^{3}}{\omega E}\right]^{0,5}
$$

Taking into account the required strength of the steel from which the railway rail was made and its resistance to "fatigue", a mathematical formula was proposed for its stress value, determining, among other things, the strength of steel for its possible "stretching" as a result of rolling a wagon wheel.

$$
\sigma_{\text {toczenia }}=0,5 \sigma_{\text {url }}
$$


In most of the cases studied, the contact pressure distribution occurs mainly in the area of the "head" of the rail and is closely related to the main stress. Experiments carried out so far show that the creation of smaller or larger loads on the rail is not related in any way to the increase in the surface depth of the railhead.

The average values of the rolling force are determined from the following equation [10]:

$$
\tau_{\text {max }}=0,3 \sigma_{\text {średnie }} \rightarrow \tau_{\text {max }}=410 \sqrt{\frac{P_{s}}{R_{w}}}
$$

As it has been shown before, the rolling and sliding occurring as a result of the wheel's influence on the rail are closely related. In addition, using the material deformation theory, you can determine the upper-pressure values that can affect the rail as a result of the rolling wheel. Thus, it was obtained

$$
\tau_{\text {górne }}=\frac{1}{\sqrt{3}} \sigma_{\text {średnie }} \rightarrow \tau_{\text {górne }}=0,3 \sigma_{\text {url }}
$$

The above expression and the criteria discussed refer to the method of making the railway rails alone, taking into account its possible deflections and wear.

\section{Mathematical model of object movement on rails}

A differential equation describing the movement of a train in a high-speed rail infrastructure in which the rail is an Euler-Bernoulli beam resting on a rigid ground is as follows [14]:

$$
E I \frac{d^{4} w}{d x^{4}}-k_{1} \frac{d^{2} w}{d x^{2}}+k w+\rho \frac{d^{2} w}{d x^{2}}+c \frac{d w}{d t}=P(x, t)
$$

where $w(x, t)$ is a function defining the lateral bending of the beam [m], E - means Young's modulus of the material made of the beam (rail), I - second moment of inertia, $\mathrm{k}$ - elasticity coefficient per bar length $\mathrm{N} / \mathrm{m}^{2}$ ), $\mathrm{k}_{1}$ - coefficient defining the abrasion of the beam in the ground $(\mathrm{N})$, - the mass of the moving beam on its specified length $[\mathrm{kg} / \mathrm{m}], \mathrm{c}-$ is the damping factor defined on a certain section of the beam $\left[\mathrm{Ns} / \mathrm{m}^{2}\right], \mathrm{P}(\mathrm{x}, \mathrm{t})$ is a function of the load of a moving object defined on a certain section of the beam $[\mathrm{N} / \mathrm{m}]$, in - the number of coordinates measured on a selected section of the beam in time $t$.

Assuming that the train together with the wagons attached to it moves in the $x$ direction (positive) in the Cartesian coordinate system with constant speed $v$, then its motion coordinates $\xi$ can be determined from the dependence (x-vt). Then substituting for equation (7) was obtained

$$
E I \frac{d^{4} w}{d x^{4}}-k_{1} \frac{d^{2} w}{d x^{2}}+k w+\rho \frac{d^{2} w}{d x^{2}}+c \frac{d w}{d t}=P(x-v t)
$$

where $P$ is the train load per beam at constant velocity $v$. The equation describing this function is the following $P(x, t)=P \delta(x-v t)$ and is determined at the point where $\mathrm{x}=0$, where $\delta(t)$ is a function Dirac.

Next, the size of $\mathrm{k}$ and $\mathrm{k}_{1}$ parameters should be determined on the basis of leads and tests carried out by Vlozova and Loetive [12]. Thus, for a single value of the surface $H$ on which the rails are mounted, the coefficients $k$ and $k_{l}$ define dependencies

$$
k=\frac{E_{s}}{H\left(1+v_{s}\right)-\left(1+2 v_{s}\right)} ; \quad k_{1}=\frac{E_{s} H}{6\left(1+v_{s}\right)}
$$


Dividing equation (8) by $E I$ it was obtained [14]:

$$
\frac{d^{4} w}{d x^{4}}-\frac{k_{1}}{E I} \frac{d^{2} w}{d x^{2}}+\frac{k}{E I} w+\frac{\rho}{E I} \frac{d^{2} w}{d x^{2}}+\frac{c}{E I} \frac{d w}{d t}=\frac{P}{E I}(x-v t)
$$

\section{Forces on the railway junction}

Commonly in modeling the mathematical relationship describing the impact of forces interacting only with the railway switch itself, it is assumed that the decisive influence on the deflection of the first train stage has the forces of pressure caused by our three switch drives, in the second section weighed by the resistance forces caused by passing the rail-track through frogs. At this point, it should be noted that both these forces have a negligible effect on the values of contact forces occurring as a result of rolling the wheel on the rail. The total lack of influence of the pressure of the switch drives is also visible on the very tip of the spire. The distance from the point of location of the index drives as a result of and the triggering of the triggered force (trigger pulse) depends on many factors, including but not limited to the speed of the train crossing the railway crossing.

In the railway junction, two zones can be defined where the control elements are damaged or the rail-track is derailed. These are the initial section in which the spire is located, while the second is a fragment where the crosses are placed.

Then, having both forces at your disposal, you can determine the normal force that the railtrack vehicle affects the entire section of the railway junction. In the considerations, the suppression of the main track was omitted due to its insignificant influence on the determined value of force. The mass of the main track was the same. However, the weight of the needle and the mass of the parts of the tracks behind the first point machine were taken into account. Therefore, the value of normal force for a train passing through the high-speed rail junction can be determined from the dependence:

$$
N=\sum F_{n z}+F_{s}+2 \alpha \cdot V \cdot \sqrt{\frac{M_{u}}{M_{u}+M_{t}}} \cdot\left(1-\frac{\pi C_{t}}{4 \sqrt{K_{t} \cdot\left(M_{u}+M_{t}\right)}}\right) \cdot \sqrt{K_{t} \cdot M_{u}}
$$

where

$N$ - normal force of a train passing through the crossover [kN]

$F_{n z}$ - clamping force of switch drives [kN]

$F_{S}$ - static force created as a result of the pressure of the wheel on the spire or the rail $[\mathrm{kN}]$

$\alpha$ - the angle of inclination between the wheel and the track [rad]

$V$ - vehicle speed rail-track $[\mathrm{m} / \mathrm{s}]$

$M_{u}$ - weight of the trolley with a wheel set $[\mathrm{kg}]$

$M_{u}$ - the mass of the needle in the further sequence of the track [kg]

$K_{t}-$ track stiffness factor $[\mathrm{MN} / \mathrm{m}]$

$C_{t}$ - track damping coefficient $[\mathrm{kNs} / \mathrm{m}]$ 
In turn, the stiffness of the crossroads track can be estimated using the elastic model of the ground on which the turnout is located. Thus, the deflection of the needle under load at a certain point on can be saved as:

where

$$
K_{t}=\frac{P}{y}=8 \beta^{3} E I
$$

where

$$
\beta=\sqrt[4]{\frac{k_{f}}{E I}}
$$

$E-$ Young's modulus

$I$ - The moment of inertia of the spire or rail

$k_{f}$ - coefficient defining the pressure caused by a single wheel $k_{f}=4,104 F_{z n}+14,61 \mathrm{MPa}$

\section{Simulation tests}

By starting to carry out computer simulations to answer the question of how the train will travel at speeds above $200 \mathrm{~km} / \mathrm{h}$ by rail junction. For this purpose, at the very beginning, firstly, the technical details of the movable object, the technical data of the railway junction were defined and the parameters of the rails included in the railway junction were determined. The defined definition of these data will allow determining the speed limits, after crossing, which may result in the derailment of the train.

For this purpose, the technical data of the train manufactured by Siemens was used (Table 1). 
Tab.1. Technical specifications of the train [15]

\begin{tabular}{|l|c|}
\hline \multicolumn{1}{|c|}{ Size } & Value \\
\hline The maximum speed achieved by the train & $250 \mathrm{~km} / \mathrm{h}$ \\
\hline The length of the train & $15 \mathrm{kV} / 16,67 \mathrm{~Hz}$ \\
\hline Power & 6 \\
\hline The number of delivery wagons & $9,9 \mathrm{MW}$ \\
\hline Traction output power & Electro-mechanical \\
\hline Type of brakes & $48(24$ drive axles $)$ \\
\hline The number of axles & $24(12 \mathrm{motor}$ units $)$ \\
\hline Number of trucks & $<18 \mathrm{t}$ \\
\hline Axle load force & 12 \\
\hline The maximum number of connected wagons & $1435 \mathrm{~mm}$ \\
\hline Track width & $28 \mathrm{~m}$ \\
\hline Body length & AC \\
\hline Power type & \\
\hline
\end{tabular}

During the simulation, the train with the technical data contained in table 1 moved along the rails with the parameters shown in table 2.

Tab. 2. Technical parameters of the rail [8]

\begin{tabular}{|l|l|}
\hline The second moment of inertia & $\mathrm{EI}=0,266 \times 106 \mathrm{Nm}^{2}$ \\
\hline Mass & $\mathrm{m}=587 \mathrm{~kg} / \mathrm{m}$ \\
\hline Damping coefficients & $\mathrm{c}=7,25 \times 103 \mathrm{Ns} / \mathrm{m}^{2}$ \\
\hline Elasticity coefficient & $53,2 \times 106 \mathrm{~N} / \mathrm{m}^{2}$ \\
\hline Pressure force & $\mathrm{F}_{0}=1 \mathrm{~N}$ \\
\hline
\end{tabular}

At the very beginning of the simulation, the numerical equations discussed in the previous sub-sections were used and an attempt was made to estimate the adjustment force necessary to switch the needle at the railway junction. 
In the next analysis, an attempt was made to evaluate the pressure exerted by the wheel on the transition from the rail to the spire. To this end, a differential equation describing train movement in high-speed trains was used and the actual parameters of the train were used, specifically in numerical calculations the technical data of the ICE-3 train [14] were used, which currently run on German high-speed railways. This test was performed on a section of the spire about 20 meters long for different train speeds: 120, 230, 350, $480[\mathrm{~km} / \mathrm{h}]$. The obtained results for the passage of a high-speed train by railroad crossovers can be used to improve and modernize the system of switch drives.
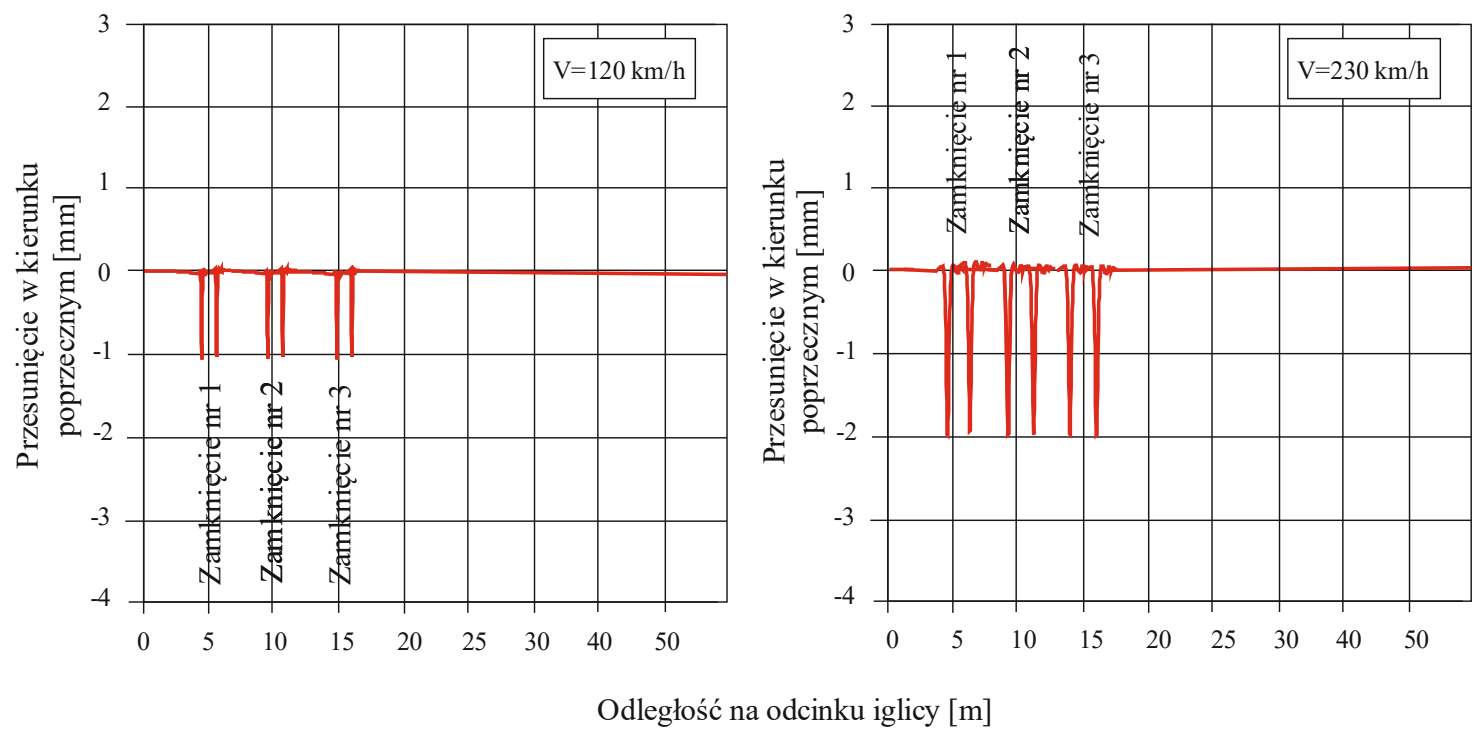

2. Graph of the rail displacement in the direction $\mathrm{Y}$ (transverse) obtained at speed $\mathrm{v}=120$

$[\mathrm{km} / \mathrm{h}]$ and $\mathrm{v}=230[\mathrm{~km} / \mathrm{h}]$
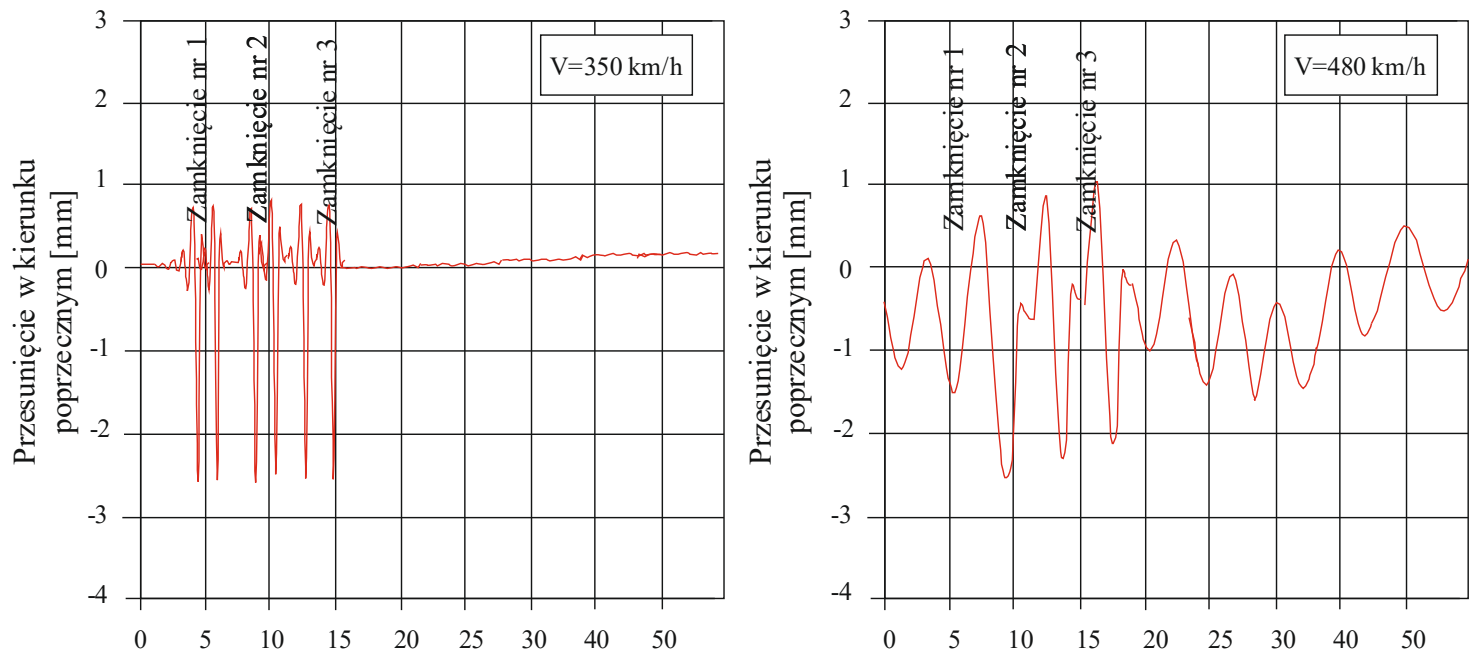

Odległość na odcinku iglicy [m]

3. Graph of the rail displacement in the direction $Y$ (transverse) obtained at speed $V=350$

$[\mathrm{km} / \mathrm{h}]$ and $\mathrm{V}=480[\mathrm{~km} / \mathrm{h}]$ 
At the end, a wheel rail contact was made on the part of the railway crossing switch. Similarly, as before, numerical calculations and knowledge used in numerical calculations were used for numerical calculations [6]. The train was tested for technical data contained in table 1, the bus parameters are included in table 2. The results from this stage of the research are presented in the following charts.

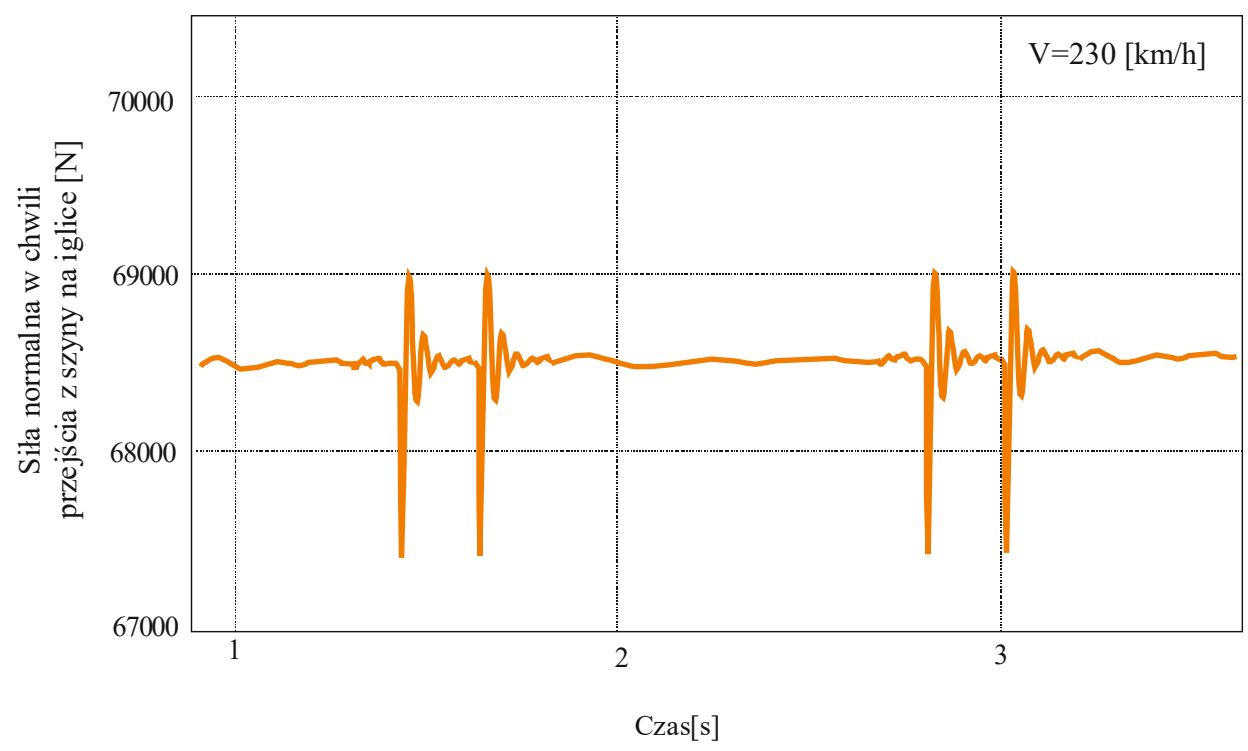

4. The course of the normal force transition of the wheel from the rail to the needle at speed $[\mathrm{v}=230 \mathrm{~km} / \mathrm{h}]$

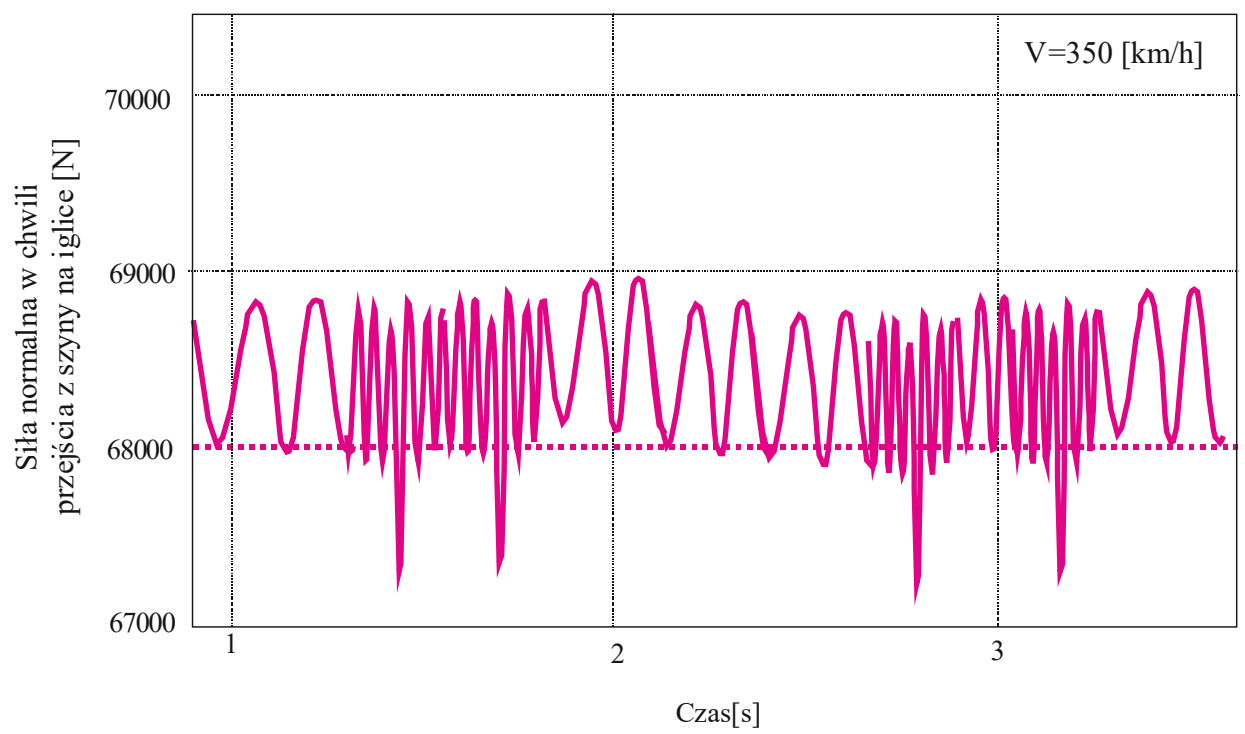

5. The course of the normal force transition of the wheel from the rail to the needle at speed [v $=350 \mathrm{~km} / \mathrm{h}]$

\section{Conclusions}

As can be seen on the basis of the presented results from the conducted simulation tests, the dynamics and speed of train movement after the switch mechanism mounted on the tracks significantly differs from the results obtained on a straight track section. This is due to the fact that the transition of the rail to the needle is made non-fluid, the entire system moves in the direction of the Y-axis in the section of turnout installation. Tests to estimate the lateral displacement, which takes place at the moment of passing through the crossover, started at a 
speed of $120 \mathrm{~km} / \mathrm{h}$, gradually increasing it, up to $480 \mathrm{~km} / \mathrm{h}$. The obtained results allow to draw the conclusion that at the time of the train crossing the railway at a speed above $200 \mathrm{~km}$ $/ \mathrm{h}$, it may derail from it, in order to prevent such effects, switch-points with setting force exceeding $7 \mathrm{kN}$. In addition, the simulations confirmed the hypothesis that the holding force of a switch machine in an environment whose temperature exceeds $28^{\circ} \mathrm{C}$ significantly decreases. On the contrary, it looks like when the air temperature will oscillate below $10^{\circ} \mathrm{C}$ its value will increase. The results obtained for the passage of a high-speed train by railroad crossovers can be used to improve and modernize the locking system of the closing closures and to determine the minimum values of the spring's spring force and its maximum resistance to movement. Bearing in mind the safety of passengers, it can be concluded that turnouts currently used in railway infrastructure may turn out to be elements exposed to faster consumption, which may indirectly cause a situation threatening the safety of passengers themselves. The presented results show the methodology of researching dynamic phenomena when traveling a train through a crossover. The results from the dynamic analysis of the train passage presented in the smallest article may be extended to determine the stability of the train when traveling through the crossover.

\section{Source materials}

[1] Cao Y., Ping W., Zhao W. H.,. Zhao C. Y, "The Influences on Turnout Dynamic Responses due to its Irregularities", Applied Mechanics and Materials, Vols. 105-107, pp. 1181-1186, 2012

[2] Chen R., Ping W.,. Wei X. K, "Influence of Conversion Deviation on Dynamic Performance of High-Speed Railway Turnout", Key Engineering Materials, Vols. 474476, pp. 1599-1604, 2011

[3] Chen R., Ping W., Song Y., "Wheel/Rail Contact Geometry of Different Wheel Tread Profile in High-Speed Railway Turnout", Advanced Materials Research, Vols. 255-260, pp. 3988-3992, 2011

[4] Chen R., Ping W., Zhao W. H., "Longitudinal Interaction between Welded Turnout on Continuous-Slab-Track and Bridge", Advanced Materials Research, Vols. 217-218, pp. 976-981, 2011

[5] Bajon W., Osiński Z., Szafrański W.: Elektryczne napędy zwrotnicowe, Wydawnictwo Komunikacji i Łączności, Warszawa 1969.

[6] Garg V., Dynamics of Railway Vehicle Systems, Elsevier Inc, 1984

[7] Iwnicki S., Handbook of Railway Vehicle Dynamics, CRC Press 2006

[8] Kisilowski Jerzy, Kowalik Rafał, Kwiecień Katarzyna „Analiza dynamiczna przejazdu pociągów szybkiej kolei przez rozjazd kolejowy", Logistyka 6/2014

[9] Kisilowski J., Knothe K., Advanced Railway Vehicle System Dynamics, WNT, Warszawa 1991,

[10] Kisilowski J., Dynamika Układu Mechanicznego Pojazd Szynowy-Tor, PWN, Warszawa 1991

[11] Kisilowski J., Współpraca taboru z nawierzchnią w Kolejach Dużych Prędkości, Logistyka

[12] Mu C. Y.,. Feng B,. Sui M. G,. Wang A. M, "Testing Research of Physical and Mechanical Properties of Snows on Railroad Switch", Applied Mechanics and Materials, Vols. 380-384, pp. 4387-4390, 2013

[13] Wang P. Design of High-Speed Railway Turnouts 1st Edition, Theory and Applications, Academic Press, 2015

[14] Xu H., Wang P., Liu D.,. Xu J. H, Chen R, "Maintenance Technologies Research of High Speed Turnout", Applied Mechanics and Materials, Vols. 97-98, pp. 114-120, 2011 